Available online at GSC Online Press Directory

GSC Biological and Pharmaceutical Sciences

e-ISSN: 2581-3250, CODEN (USA): GBPSC2

Journal homepage: https://www.gsconlinepress.com/journals/gscbps

(RESEARCH ARTICLE)

\title{
Microbiological quality of cooked skewers sold in the municipality of Adjame in Abidjan (Côte d'Ivoire)
}

\author{
Koffi Maïzan Jean-Paul Bouatenin 1, ${ }^{*}$, Wahauwouélé Hermann Coulibaly ${ }^{1}$, Kohi Alfred Kouame 1, Zamblé Bi \\ Irié Abel Boli ${ }^{1}$ and Koffi Marcellin Dje ${ }^{1}$ \\ ${ }^{1}$ Department of Food Sciences and Technology, Laboratory of Biotechnology and food Microbiology, University Nangui \\ Abrogoua, Abidjan, Côte d'Ivoire, 02 BP 801 Abidjan 02.
}

Publication history: Received on 07 September 2020; revised on 20 October 2020; accepted on 24 October 2020

Article DOI: https://doi.org/10.30574/gscbps.2020.13.1.0336

\begin{abstract}
The objective of this study is to evaluate the microbiological quality of skewers sold on the street in order to define an approach to protect consumer health. A consumption survey was carried in the commune of Adjame because in this commune, the sale and consumption of beef skewers meat is widespread. For this study, 108 peoples were interviewed. In the same way, the enumeration of certain microorganisms was carried out. Results had showed that the number of male consumers was equal to that of female consumers (50\%) but majority of consumers were single (82\%). Among consumers, $52 \%$ developed discomfort at least once after eating beef skewers meat. The symptoms of these discomforts were mainly diarrhea (18\%), abdominal aches (11\%) and vomiting (6\%), These discomforts lasted at least 1 day to 3 days and $6 \%$ of these patients were hospitalized. In addition, microbiological analyses reveal the presence of microorganism such as Staphylococcus aureus, Escherichia coli, mesophilic aerobic germs, and coliforms with microbial loads higher than the European Community (EC) standard $n^{\circ} 2073 / 2005$ on ready-to eat, notably cold sold skewers. The mesophilic aerobic flora counted after the analysis of the cold-cooked skewers was $9.7 \pm 2.7 \times 10^{8} \mathrm{CFU} / \mathrm{g}$ and those cooked hot were $6 \pm 1.1 \times 10^{6} \mathrm{CFU} / \mathrm{g}$. So, our samples are highly contaminated. Thus, the sellers and consumers of skewers should receive training in food hygiene. Particular attention should be paid to all causes of food poisoning.
\end{abstract}

Keywords: Microbiological; Health risks; Consumers; Cooked skewers

\section{Introduction}

Meat is considered a food of choice because of its nutritional value. Its high protein content makes it an essential food for a balanced diet. World meat production is estimated at 336.4 millions tonnes in 2018 [1]. In Côte d'Ivoire, it accounts for $37 \%$ of the meat consumed [2] because of the increasing price of meat products. In addition, the high population growth is contributing to a steady increase in demand and consumption of beef [3, 4]. In Abidjan, there are several points of consumption and sale of cooked beef outside the home with various forms of cooking, namely: cooked steaks, cooked skewers and meat cooked in sauce. Thus, barbecues commonly known as cooked meats or "choukouya" and cooked skewers are consumed in the streets and during ceremonies by a large segment of the population. However, due to poor hygienic conditions at the time of sale, the consumption of these foods leads to many cases of collective foodborne illness around the world [4]. In Côte d'Ivoire, for example, the Centre for Disease Control (CDC) estimates that 3.6 to 7.1 million Ivorians have been affected by a foodborne illness. Of these, 2.1 to 5 million incidents are attributed to meat and poultry consumption [5]. The number of deaths attributed to foodborne pathogens ranged from 2695 to 6587, of which 1436 to 4232 were related to meat and poultry consumption [6]. Among the germs responsible

\footnotetext{
* Corresponding author: Koffi Maïzan Jean-Paul BOUATENIN

Department of Food Sciences and Technology, Laboratory of Biotechnology and food Microbiology, University Nangui Abrogoua , Abidjan, Côte d'Ivoire, 02 BP 801 Abidjan 02.
} 
for collective foodborne illness due to meat consumption, Salmonella, Staphylococcus aureus, Bacillus cereus and Escherichia coli have been mentioned. In Côte d'Ivoire, Salmonella, Clostridium, Staphylococcus and Escherichia coli have been isolated from these foods [7, 8]. [9] reported that the presence of pathogenic microorganisms in meat results from contamination of carcasses during slaughter from the gastrointestinal contents, animal skins and feet, premises and equipment used, staff hands and clothing, carcass washing water and even ambient air. The quality of meat products has become a major concern for consumers in many countries. Work carried out in the sector of the sale of cooked skewers at the street level in some countries has made it possible to identify specific problems, propose and implement strategies to control their negative effects, while maintaining the positive aspects, mainly the socio-economic aspects [7]. The objective of this study is to evaluate the microbiological quality of skewers sold on the street in order to define an approach to protect consumer health and to provide solutions through the implementation of good hygiene and manufacturing practices at the sites where this meat is sold.

\section{Material and methods}

\subsection{Biological material}

The biological material consists of cooked beef skewers in two commercial forms: hot sold skewers and cold sold skewers (Figure 1). The Samples of cooked beef skewers were collected from vendors in the city of Abidjan mainly in the commune of Adjame.

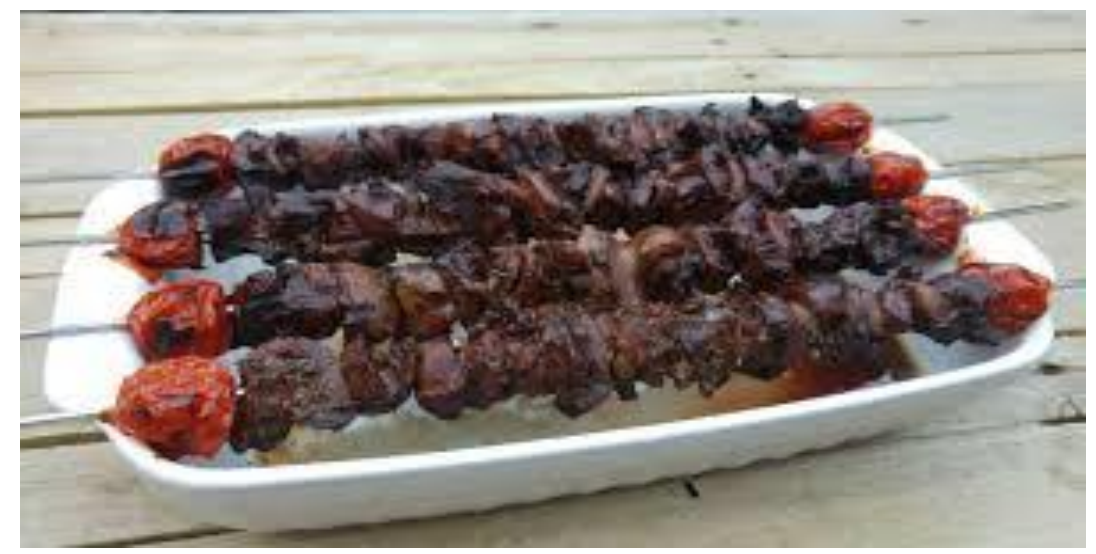

Figure 1 Skewer of ready-to-eat cooked beef

\subsection{A survey form}

A survey sheet has been prepared on the preference and risk system for beef skewers consumption. To this end, an observation grid was used to determine the characteristics of the consumption chain and the risk profile of beef skewers consumers.

\subsection{Study sites and population}

The surveys were conducted in the commune of Adjame in Abidjan city. In this commune, the sale and consumption of beef skewers meat is widespread and they host several sites for the sale of ready-to-eat beef skewers. For this study, 108 people were interviewed

\subsection{Size of individuals to investigate}

The sample size for this study was calculated using the formula described by [10] for a non-exhaustive independent sample

$$
\mathrm{n}=\mathrm{t}^{2} \cdot \frac{\mathrm{p} \cdot(1-\mathrm{p})}{\mathrm{e}^{2}}
$$


With $\mathrm{n}$ : the sample size, e: the margin of error, $\mathrm{t}$ : the margin coefficient deduced from the confidence rate, $\mathrm{p}$ : the population in the study area. The sample for each area was obtained using the probability method proportional to the size of households in each locality [11] based on data from the general population census of Côte d'Ivoire [12]

\subsection{Data collection}

A bibliographical research and a field survey of different places of consumption of cooked beef skewers meat in the sites of the commune of Adjame were carried out. This month-long phase collected some data from the literature, observed consumers, established relationships with consumers and producers, and designed a survey questionnaire on cooked beef skewers consumption. This questionnaire was tested on about 108 consumers in different sites concerned. The results of this pilot phase were not considered in the final result because most of these results were incorrect. The final questionnaire was submitted to consumers at the various sites. On the sites, the questionnaire is explained point by point to consumers. The questions were multiple-choice questions with the possibility of 2 to 6 proposed answers or questions with yes or no and true or false answers. The final questionnaire was structured around three main points:

- The respondent's profile

- Knowledge and consumption of cooked beef skewers by the respondent

- Malaise contracted by the respondent after consumption of cooked beef skewers.

\subsection{Sampling}

The two commercial forms of ready-to-eat of cooked beef skewers (hot sold skewers and cold sold skewers) were collected from ten sites of Adjame in the city of Abidjan. In each site, five vendors of beef skewers meat were selected. At each collection, two samples of each type of skewer for a quantity of about $100 \mathrm{~g}$ were purchased from each seller. A total one hundred samples were selected for this study during the period October to December 2018.After sampling, the samples were placed in a cooler containing ice cream cooler and transported to the laboratory within one hour of sampling for the various analyses.

\subsection{Isolation and enumeration of bacteria}

The mother solution and decimal dilutions were performed according to the methods of [13]. For the analyses, ten grams (10 g) of samples were crushed and taken under sterile conditions created by the flame of a bunsen burner and mixed in a "stomacher" bag with $90 \mathrm{~mL}$ of buffered peptone water (AES Laboratoire, COMBOURG France) previously sterilized and used as diluent. Mesophilic aerobic germs (MAG) were counted on PCA (Plate count Agar) agar (Oxoid LTD, Basingstore, Hamsphire, England) after two days of incubation at $30^{\circ} \mathrm{C}$ according to AFNOR Standard NF V08051,1999. Yeasts and moulds were enumerated on plates of Sabouraud chloramphenicol agar (Fluka, Bochemica 89579, Sigma-Aldrich Chemie $\mathrm{GmbH}$, Inda) incubated at $30^{\circ} \mathrm{C}$ for 4 days. The research and counting of Staphylococcus aureus were done on Baird Parker agar after one day incubation at $30^{\circ} \mathrm{C}$ using [14] method. The quantitative estimation of spores of $B$. cereus was performed by a standard plate counting method. Isolations were achieved from heat-treated dilutions by plating on mannitol egg yolk polymyxin B agar [15]. Presumptive colonies of B. cereus were randomly selected based on characteristic colony feature, purified on the same medium, and identified by morphological, cultural, and biochemical characteristics according to the documented procedures [16]. Enumeration of coliforms was carried out using plates of Violet Red Bile Lactose agar (VRBL, Merck 10660, Merck, and Darmstadt, Germany). The cultures were incubated for $48 \mathrm{~h}$ at $30^{\circ} \mathrm{C}$ for total coliforms. The eosin methylene blue agar (Becton Dickinson GmbH, Heidelberg, Germany) was used to particularly enumerate and isolate E. coli, which grows on the medium giving a distinctive metallic green sheen colony. The isolation and enumeration of Salmonella was carried out using [17] method in several steps. This was achieved by pre-enrichment in a non-selective medium, followed by enrichment in a selective medium and culture on selective agar. For enrichment in non-selective or pre-enrichment media, a mass of Twenty-five grams of samples were homogenized with $225 \mathrm{~mL}$ of peptonned water in a sterile jar, incubated at $37^{\circ} \mathrm{C}$ for 24 hours. For selective recording, one milliter $(1 \mathrm{~mL})$ of the pre-enriched culture was transferred using a sterile pipette into $10 \mathrm{~mL}$ of previously prepared sterile Rappaport Vassililiadis broth and incubated for 24 hours at $37^{\circ}$ C. Salmonella enumeration was performed on Salmonella-Shigella agar (Oxoid). Each enrichment culture was streaked on Shigella-Salmonella (SS) agar and incubated at $37^{\circ} \mathrm{C}$ for 24 hours. On Salmonella-Shigella agar, the presumptive colonies were colourless, transparent, with or without a black centre.

\subsection{Statistical analysis}

Software R. 3-01, ANOVA method with Duncan post-hoc test, significance level 5\% was used. This software made it possible to calculate the means, the standard deviations of the microbiological parameters. It also made it possible to compare the means of the microbiological parameters of the samples and to determine whether the differences observed in the means of the microbiological parameters are significant at the $5 \%$ threshold. The survey results were 
processed by the statistical software "Epi Info 2004" version August 2005 produced by the Division of Public Health Surveillance and Informatics Epidemiology Program Office, MS K74, Centers for Disease Control and Prevention (CDC) Atlanta Georgia 30341-3717. This software had made it possible to calculate the frequencies of the variables. As for the completion of the main correspondence analysis (MCA), the XLSAT software version 2010. 4.04 was used.

\section{Results and discussion}

The purpose of this study was to assess the importance beef skewers meat consumption and the risks that consumers of this meat may incur in order to provide solution through the implementation of good hygiene and manufacturing practices at the sites where this meat is sold in the commune of Adjame in Abidjan city (Côte d'Ivoire). In this commune, the sale and consumption of beef skewers meat is widespread and they host several sites for the sale of ready-to-eat beef skewers. For this study, 108 people were interviewed. Thus, the figure 2 showed that the consumption of beef skewers meat is part of people's eating habits.

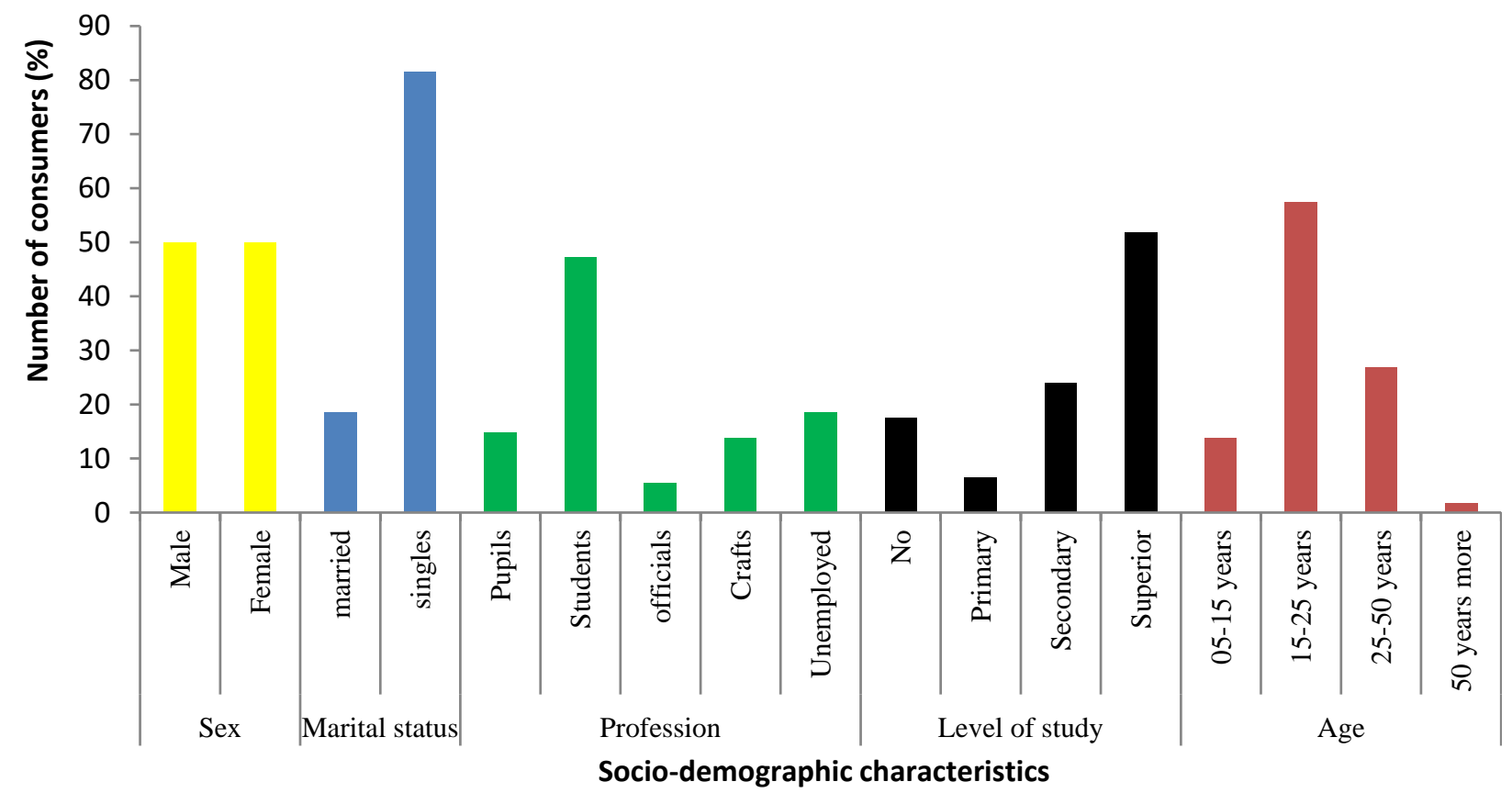

Figure 2 Socio-demographic distribution of consumers

The number of male consumers was equal to that of female consumers (50\%). The majority of consumers are single (82\%) and have at least the level of higher education (52\%). The biggest consumers are students (47\%) with an age range between 15 and 25 years (57\%). These results are in agreement with those of [18] on the microbial risks associated with the consumption of braised beef commonly and locally called Choukouya in Côte d'Ivoire. Indeed, beef skewers is a meat within the reach of low-income earners and students are part of this social class. The strong urban population growth of these municipalities is one of the factors favouring this consumption. In addition, single men, after work, prefer to eat street foods to avoid culinary chores at home. Among consumers, $52 \%$ developed discomfort at least once after eating beef skewers meat. The symptoms of these ailments are mainly diarrhea (18\%), abdominal aches (11 $\%$ ) and vomiting (6\%), These discomforts lasted at least 1 day to 3 days and $6 \%$ of these patients were hospitalized (Table 1).

This is due to contamination of skewers by pathogenic microorganisms. Indeed, microbiological analyses reveal the presence of microorganism such as Staphylococcus aureus, Escherichia coli, mesophilic aerobic germs, and coliforms with microbial loads higher than the European Community (EC) standard n²073/2005 on ready-to eat, notably cold sold skewers. Beef skewers presents a health risk for the consumer. These germs are often responsible for food poisoning in humans [19]. The mesophilic aerobic flora counted after the analysis of the cold-cooked skewers was $9.7 \pm 2.7 \times 10^{8}$ and those cooked hot were $6 \pm 1.1 \times 10^{6} \mathrm{CFU} / \mathrm{g}$ (Table 2). 
Table 1 Discomforts related to the skewers consumption

\begin{tabular}{|l|c|c|}
\hline & Number of consumers & Frequency (\%) \\
\hline Discomfort ( $\mathrm{n}=108)$ & 56 & 52 \\
\hline Yes & 52 & 48 \\
\hline No & & \\
\hline Symptoms (n=108) & 4 & 3.7 \\
\hline Fever & 6 & 5.6 \\
\hline Vomiting & 19 & 17.6 \\
\hline Diarrhea & 1 & 0.9 \\
\hline Belly bloat & 12 & 11.1 \\
\hline Abdominal pain & 14 & 13 \\
\hline Other symptoms & 52 & 48.1 \\
\hline No & & 17.6 \\
\hline Duration of the discomfort (n=108) & 19 & 15.7 \\
\hline 1 day & 17 & 15.7 \\
\hline 2 days & 17 & 2.8 \\
\hline 3 days & 3 & 48.1 \\
\hline 3days more & 52 & \\
\hline No & & 5.5 \\
\hline Hospitalization (n=108) & 6 & 46.3 \\
\hline Hospitalized & 50 & 48.1 \\
\hline No hospitalized & 52 & \\
\hline Healthy consumers & & \\
\hline
\end{tabular}

Table 2 Microbial loads Skewer of cooked beef meat

\begin{tabular}{|l|l|l|l|}
\hline \multicolumn{4}{|c|}{ Skewers } \\
\hline Microbial load (CFU/g) & Sold hot & Sold cold & Standards \\
\hline AM & $(6 \pm 1.1) \times 10^{6 \mathrm{a}}$ & $(9.7 \pm 2.7) \times 10^{8 \mathrm{~b}}$ & $<5.10^{5}$ \\
\hline E. coli & $(0.7 \pm 0.2) \times 10^{1 \mathrm{a}}$ & $(1.4 \pm 0.4) \times 10^{3 \mathrm{~b}}$ & $<10^{3}$ \\
\hline Coliforms total & $(1 \pm 0.5) \times 10^{3 \mathrm{a}}$ & $(1.2 \pm 0.3) \times 10^{5 \mathrm{~b}}$ & $<10^{3}$ \\
\hline Bacillus & $(1.8 \pm 0.9) \times 10^{1 \mathrm{a}}$ & $(4.4 \pm 2.1) \times 10^{1 \mathrm{a}}$ & $<10^{2}$ \\
\hline Staphylococci & $(3.8 \pm 0.1) \times 10^{4 \mathrm{a}}$ & $(2.9 \pm 0.8) \times 10^{3 \mathrm{~b}}$ & $<10^{2}$ \\
\hline Yeasts and Moulds & $(5 \pm 1) \times 10^{3 \mathrm{a}}$ & $(2.1 \pm 1.6) \times 10^{4 \mathrm{~b}}$ & $<5.10^{2}$ \\
\hline Salmonella & $\mathrm{absence}$ & Presence & Absence \\
\hline
\end{tabular}

Values are means of three determinations. In a line, means values followed by different superscript are statistically different (Duncan multiple test range at $\mathrm{P}<0.05)$, AM: aerobic mesophiles, E. coli: Escherichia coli

The presence of such microorganisms in samples could be due to an after-cooking contamination skewers by the contact with air. These germs include bacteria responsible for alteration and which most often sign a poor state of preservation [20]. Total coliforms were detected at $1.2 \pm 0.3 \times 10^{5} \mathrm{CFU} / \mathrm{g}$ in cold skewers and $1 \pm 0.5 \times 10^{3} \mathrm{CFU} / \mathrm{g}$ in hot skewers. Among these total coliforms, $E$. coli is represented at a load of $0.7 \pm 0.2 \times 10^{1} \mathrm{CFU} / \mathrm{g}$ and $1.4 \pm 0.4 \times 10^{3} \mathrm{CFU} / \mathrm{g}$ respectively for hot and cold skewers. The average loads of total coliforms, staphylococci and yeasts and moulds for both types of skewers are higher than the norm. The presence of Staphylococcus aureus at unsatisfactory levels may be indicative of poor personal hygiene by food handlers involved in the cooking of skewers meat and/or poor temperature control [21]. Indeed, the extensive handling normally associated with the preparation of skewer lends itself to contamination by food 
handlers if good hygienic practices are not implemented. Unavoidable contamination usually will add coliforms to the product. The high number of coliforms is also a sign of unsanitary conditions and/or postprocessing contamination. This contamination of beef meat skewers said to be due in the cooking and selling places of commercial beef meat skewer [22]. The genera Salmonella has been observed in cold sold skewers whereas according to the standard it must be absent in $10 \mathrm{~g}$ (Table 2). The beef meat skewers were sold on the street, often near sewers and in the open air, exposing the food to microbial contamination from the environment, air and dust. Moreover, according [7], poor hygiene practices, encountered in skinning and evisceration operations during the production of meat carcasses, are known to be particularly risky factors, as they can lead to contamination of the meat by several pathogens. Thus, according to the criteria of [24] standard, twelve samples of skewers sold on low heat were analyzed and found to comply with microbiological specifications. As for samples of skewers sold cold, not all samples comply with microbiological specifications (Table 3).

Table 3 Conformity of the skewer samples analysed with the criteria of the AFNOR 2004 Standard

\begin{tabular}{|l|c|c|c|}
\hline Skewers & Samples analyzed & Samples conforming & Samples no conforming \\
\hline Hot sold skewers & 50 & 12 & 38 \\
\hline Cold sold skewers & 50 & 0 & 50 \\
\hline
\end{tabular}

So, our samples are highly contaminated. However, this contamination rate could be lower if the use of heat was systematic. We can therefore say that contamination would often be secondary. It is located, after the passage of the meat to the fire, during the setting in small pieces followed by the seasoning. All these operations take place in an atmosphere contaminated with dirty equipment.

\section{Conclusion}

The general objective of this study was to evaluate the microbiological quality of skewers sold on the street. Skewers sold on low heat and skewers sold cold are not of satisfactory microbiological quality. Skewers sold cold represent a higher risk of toxi-infection than skewers sold on low heat due to the high load of total coliforms, E. coli and Salmonella.

\section{Compliance with ethical standards}

\section{Acknowledgments}

The authors are grateful the Sellers and Consumers of beef Skewers meat who freely agreed to participate in this study.

\section{Disclosure of conflict of interest}

Authors have no conflict of interest regarding the publication of paper.

\section{Statement of informed consent}

Informed consent was obtained from all individual participants included in the study.

\section{References}

[1] FAO. Overview of global meat market developments in 2018. Meat Market Review; 2019.

[2] Anonymous. Breeding cattle, sheep and goats. Cote d'Ivoire », Economic Mission in Abidjan; 2005.

[3] Bricas N. Cadre conceptuel sur l'analyse de la dynamique de la consommation alimentaire urbaine en Afrique. GCP/RAF/309/BEL-FRA; 1996.

[4] Zoro EG. Apports de l'information géographique dans l'élaboration d'un indicateur de développement urbain: Abidjan et l'ile de Montréal. Thèse Univ. Sherbrooke; 2001. 123p.

[5] Morris GJ. Current trends in human diseases associated with foods of animal origin JAVMA; 1996 (12) : 20452047. 
[6] Dicksons JS, Anderson ME. Microbiological decontamination offood animal carcasses by washing and sanitizing systems. A review. J. Food Prat; 1992 (55 ) : 133-140.

[7] Food and Agriculture Organization/World Health Organization. Système national de sécurité sanitaire des aliments et ses impacts socio-économiques et sanitaires (préparé par la Côte d'Ivoire). Document de séance 16, Conférence régionale FAO/OMS sur la sécurité sanitaire des aliments pour l'Afrique. Harare, Zimbabwe; 2005. P. $1-6$.

[8] Koffi-Nevry R, Judicaël ACB, Assemand EF, Wognin AS, Koussemon M. Origine de contamination fécale de l'eau d'arrosage de la laitue cultivée dans d'Abidjan. Journal of Applied Biosciences; 2012 (52): 3669-75.

[9] Plusquellec A. Viande et produits carnés . In Bourgeois CM., Leveau J.M. (ed.). Techniques d'analyse et de contrôle dans les lAA,; 1991 (3) : 360-378.

[10] Israel DG. Determining Sample Size . University of Florida, Fact Sheet PEOD; 1992.

[11] Bartlett EJI, Kotrlik WJ, Higgins CC. Organizational Research: Determining Appropriate Sample Size in Survey. Research. Information Technology, Learning, and Performance Journal; 2001 (19) 43 -50.

[12] INS (Institut National de la Statistique). Recensement général de la population et des habitations, données sociodémographiques des localités. Région des Lagunes. République de Côte d'Ivoire, Tome I; 1998. P.83

[13] Djeni NT, N'Guessan KF, Toka DM, Kouamé. KA, Djè, KM. Quality of attiéké (a fermented cassava product) from the three main processing zones in Côte d'Ivoire. Food Research International Journal; 2011(44): 410-416, doi:10.1016/j.foodres.2010.09.032.

[14] Capita R, Alonso-Calleja MCB, Garcia-Fernandez MC. Assessment of Baird Parker agar as screening test for determination of Staphylococcus aureus in poultry meat. Journal Microbiology; 2001 (39): 321-325.

[15] Mossel DAA, Koopman MJ, Jongerius E. Enumeration of Bacillus cereus in foods. Appl.Microbial; 1967 (15): 650 653.

[16] Cappuccino JG, Sherman N. Microbiology: A Laboratory Manual. Pearson Education, Singapore; 2004. P.491.

[17] Hendriksen RS. Laboratory Protocols Level 1: Training Course Isolation of Salmonella. A Global Salmonella Surveillance and Laboratory Support Project of the World Health Organization. 4th edn. Geneva: WHO; 2003.

[18] Dibi EAB, Zita E. BN, Djedjro CA, Tano K., Assidjo EN. Risques microbiens liés à la consommation de la viande bovine braisée «Choukouya » en Côte d'Ivoire. International Journal of Innovation and Applied Studies ISSN 2028-9324; 2017 (3) : 496-507

[19] Easa S. M. H, «The microbial quality of fast food and traditional fast food». Nat Sci 8, art; 2010. P.10

[20] Rozier J. Comprendre et pratiquer l'hygiène en cuisine. NIillau: Irnp.NIaury; 1990. P.200

[21] Adams M R, Moss MO. Food microbiology. R.Soc. Chem. Sci., Park Cambridge; 2000.P. 447.

[22] Heredia N, Garcia S, Rojas G, Salazar L. Microbiological Condition of Ground Meat Retailed in Monterrey, Mexico. Journal of Food Protection; 2001 (64) : 1249-1251

[23] Salifou CFA, Salifou S, Tougan PU, Ahounou GS, Youssao AKI. Evaluation de l'hygiène du procédé d'abattage aux abattoirs de Cotonou-Porto-Novo à l'aide d'examen bactériologique de surface.13e Journées des Sciences du Muscle et de la Technologie de la Viande, 19 et 20 octobre 2010 à Clermont Ferrand, France; 2010. P. 175-176.

[24] AFNOR (Association Française de Normalisation). Analyse microbiologique : méthodes horizontales Paris : Association Française de Normalisation (AFNOR) :1,521-31. Approvisionnement et distribution alimentaire des villes de l'Afrique francophone, FAO-CIRAD; 2004. $50 \mathrm{p}$ 